\title{
Ultrasonic IR thermographic inspection of graphite epoxy composite: a comparative study of piezoelectric and magnetostrictive stimulation
}

\author{
W. SWIDERSKI ${ }^{*}$ and V. VAVILOV ${ }^{2}$ \\ ${ }^{1}$ Military Institute of Armament Technology, 7 Wyszynskiego Str., 05-220 Zielonka, Poland \\ ${ }^{2}$ Tomsk Polytechnic University, 7 Savinykh Str., Tomsk, 634028 Russia
}

In this paper the experimental results of piezoelectric and magnetostrictive ultrasonic stimulation are comparatively analyzed in the evaluation of impact damage in a graphite epoxy composite sample chosen for a round robin test. By comparing theoretical and experimental results, it is shown that the equivalent power of internal friction can reach some hundreds mill watt per a single crack.

Keywords: nondestructive testing, IR thermography, ultrasonic, graphite epoxy composite.

\section{Introduction}

Peculiarities of ultrasonic IR thermographic testing of graphite epoxy composites are relatively well studied, at least at a qualitative level. The phenomenon of mechanical hysteresis seems to be vanishing in the range of typically used ultrasonic frequencies and electrical powers (from 20 to 40 $\mathrm{kHz}$ and up to a few $\mathrm{kW}$, respectively), therefore, a sound composite remains 'cold' during stimulation, while noticeable temperature signals appear in defective areas due to internal friction.

Ultrasonic IR thermography combines the principle of 'optimal' (dark-field) heating and the feasibility of both lock-in and pulsed data analysis. The origin of this research can be traced to the 1980s (see the milestone paper by Reifsnider $e t$ al. [1]). In its present form ultrasonic IR thermographic nondestructive testing (NDT) is being developed by several world research teams, merely to mention Busse et al. who use the term "ultrasonic lock-in thermography" (ULT) [2-5], Thomas et al. who prefer the term "sonic IR imaging", or "thermosonics" [6], and Burke and Miller who suggested the terms "VibroIR" and "SonicIR" [7], as well as Morbidini et al. [8], Renshaw et al. [9] and Homma et al. [10].

Until present, most research in this area has been done by using piezoelectric units, for example, those originally intended for welding of plastics. In this case, a problem of a good coupling between a horn and a tested material typically arises. In Russia, historically, powerful ultrasonic waves have been generated by developing magnetostrictive devices of whose efficiency is less affected by a contact quality. Such devices are widely used for the cleaning and surface treatment of metals. However, under magnetostric-

\footnotetext{
*e-mail: waldemar.swiderski@wp.pl
}

tive stimulation, a point-like surface damage of composites frequently occurs in a contact area where an indentor hits surface. In both stimulation cases, the magnitude of ultrasonic energy that is effectively absorbed by a host material and/or diffracted by defects has not been well studied. The comparison between these two types of ultrasonic excitation in application to aluminium parts was described in Ref. 11. In this paper the experimental results of applying piezoelectric and magnetostrictive ultrasonic stimulation are comparatively analysed in the evaluation of impact damage in a graphite epoxy composite sample chosen for a round robin test.

\section{Test sample and experimental set-ups}

A round-robin test has been fulfilled on a 15-ply carbon fibre reinforced plastic (CFRP) sample (thickness of 11.6 $\mathrm{mm}$ ) with impact damage at two laboratories at Military Institute of Armament Technology (MIAT), Poland, and Tomsk Polytechnic University (TPU), Russia. The resistance of composites toward impact damage can be evaluated by measuring the ballistic limit $\mathrm{V}_{50}$ with a standard striking fragment having mass of $1.1 \mathrm{~g}$. Both surfaces of the sample together with the scheme of a bullet simulating the fragment are shown in Fig. 1 (note that $\langle\mathrm{F} »$ specifies the front (impacted) sample surface, while «R» means the rear surface). Ballistic tests allow for the comparison of different materials, first of all, in regard to their surface density. The fragment used for impacting the sample is recommended in the corresponding Polish standard. The respective NATO document describing requirements to this test is STANAG 2920 "Ballistic test method for personal armour".

The sample size is $148 \times 130 \times 11.6 \mathrm{~mm}$, mass $-313 \mathrm{~g}$, composite density $-1402 \mathrm{~kg} / \mathrm{m}^{3}$. Thermal properties of 


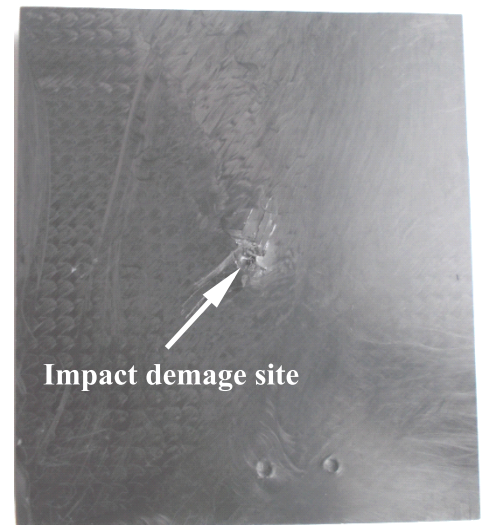

(a)

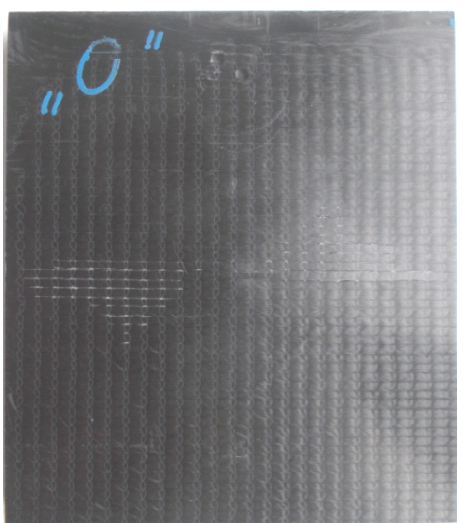

(b)

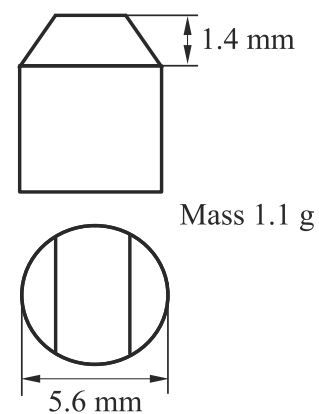

(c)

Fig. 1. Graphite epoxy composite sample (11.6 mm-thick) used in the round-robin test: (a) - front (F) surface, (b) - rear (R) surface, (c) - bullet simulating fragment.

CFRP have been evaluated by using the Parker's flash method in its two-sided implementation. The R-surface experimental temperature response in a sound area [Fig. 2(a)] was fitted with a theoretical curve calculated in a 2D cylindrical geometry by using ThermoCalc-2D software [Fig. 2(b)]. The best fit was obtained with the following CFRP properties: thermal diffusivity $\alpha=3.38 \cdot 10^{-7} \mathrm{~m}^{2} / \mathrm{s}$, thermal conductivity $K=0.61 \mathrm{~W} /(\mathrm{m} \cdot \mathrm{K})$, density $\rho=1400 \mathrm{~kg} / \mathrm{m}^{3}$ and heat capacity $C=1290 \mathrm{~J} /(\mathrm{kg} \cdot \mathrm{K})$.

The experiments at MIAT have been fulfilled by means of a FLIR SC 7600 IR imager (image format $320 \times 256$, acquisition frequency $5 \mathrm{~Hz}$, up to 1600 images in a sequence). Continuous ultrasonic stimulation was performed with a piezoelectric unit at the frequency of $30 \mathrm{kHz}$ with the power from 80 to $130 \mathrm{~W}$ (maximum allowed power up to $2 \mathrm{~kW})$.

The TPU experimental set-up included a NEC TH-9100 IR imager $(320 \times 240,10 \mathrm{~Hz})$ and a magnetostrictive unit ( $22 \mathrm{kHz}$, up to $2.5 \mathrm{~kW}$ ) with the stimulation time being up to 5 s. In order to avoid local damage in a sample, a 0.3 mm-thick steel gasket was used for coupling.

\section{Results}

The fact that optical (surface) and ultrasonic (volumic) stimulation produce very different patterns of subsurface defects was described elsewhere [3]. A very simple explanation to this fact is that heat flux propagating from surface in-depth experiences the greater disturbance on thicker defect sections because of a greater defect thermal resistance. Oppositely, ultrasonic stimulation is more effective for thinner (even 'kissing') defects because of a more intensive friction. Therefore, optical stimulation better exhibits big defects [12-14], while ultrasonic thermography might be good for detecting small ones.

The power generated by delaminations and crack-like defects in graphite epoxy composite have been evaluated by assuming that subsurface defects operate as heat sources of constant power in the case of continuous ultrasonic stimula-

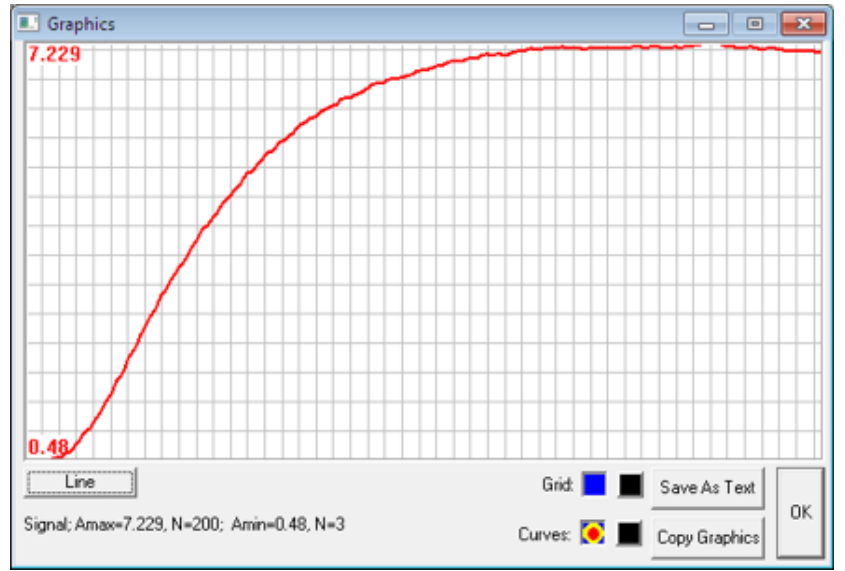

(a)

$\mathrm{T}\left({ }^{\circ} \mathrm{C}\right)$

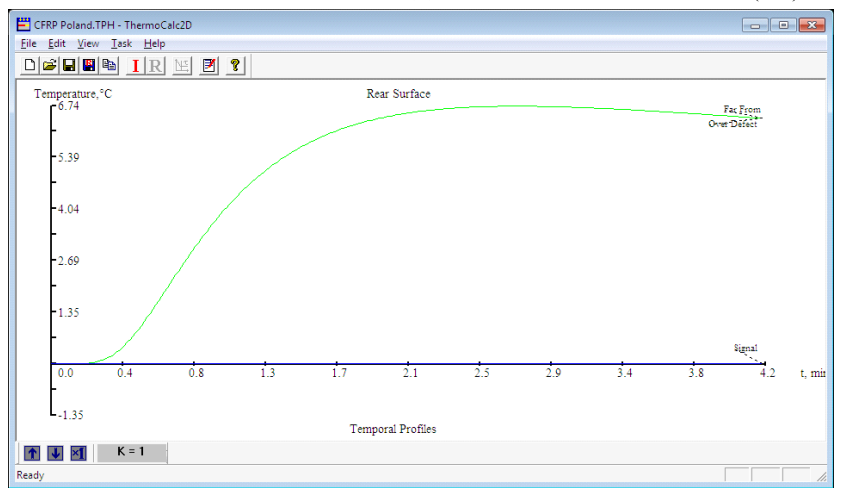

(b)

Fig. 2. Best fit of experimental (a) and theoretical (b) R-surface temperature responses of $11.6 \mathrm{~mm}$-thick CFRP test sample.

tion. By fitting the experimental temperature signals in defect areas with theoretical predictions following from a 3D heat conduction model, it has been found that the equivalent defect power may reach some hundreds of mill watt (see more details in Ref. 15).

The qualitative comparison of IR thermograms of impact damage obtained with the above-mentioned types of stimulation follows from Fig. 3. The superficial exfoliation 


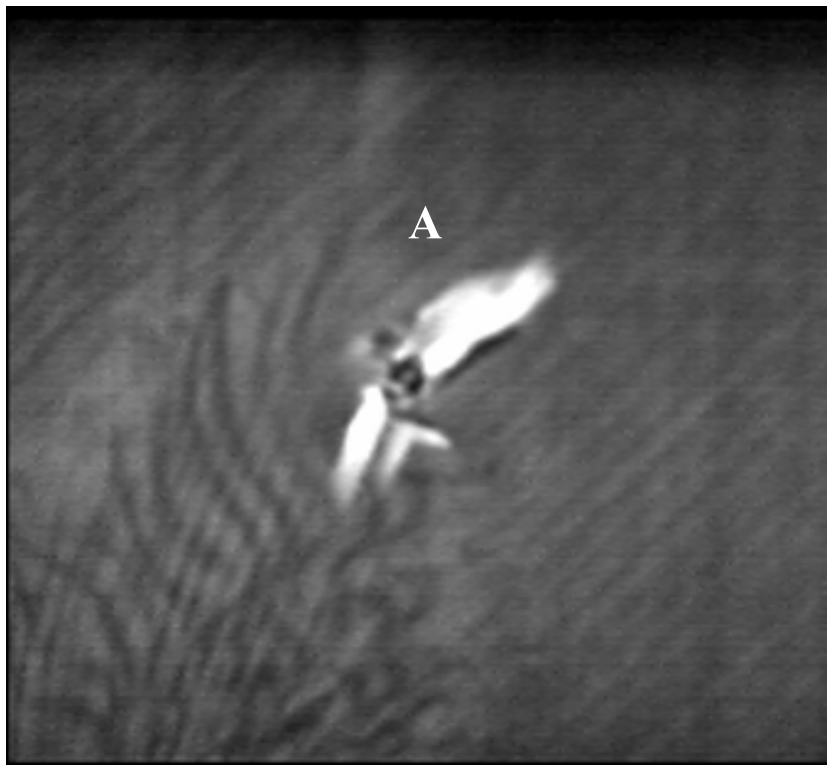

(a)

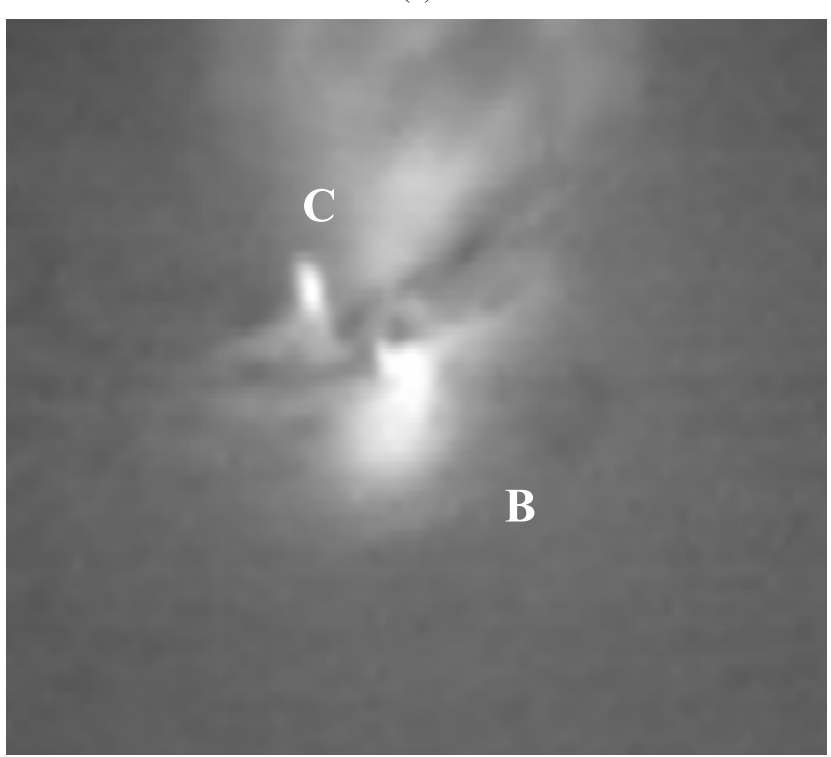

(b)

Fig. 3. Front surface source images as a result of optical (a) and ultrasonic (b) stimulation (NEC TH-9100 IR imager, halogen lamps, magnetostrictive unit, $22 \mathrm{kHz}, 600 \mathrm{~W}$ ).

(area A) surrounding the impacted point is well seen due to strong optical overheating while ultrasonic excitation reveals some other subsurface features, probably, corresponding to more subtle but deeper crackings (areas B and C). It is worth noting that, even if a multiple cracking used to penetrate through the whole sample reaching its rear surface, the large sample thickness prevented one-sided detection of deeper defects, particularly, in the case of optical heating whose detection limit is typically evaluated as $4 \mathrm{~mm}$ for graphite epoxy composite.

A more detailed indication of the F-surface impact damage has been obtained by using piezoelectric heating in conjunction with the SC 7600 IR imager (Fig. 4). In this case, the defect indication looked somewhat different from the

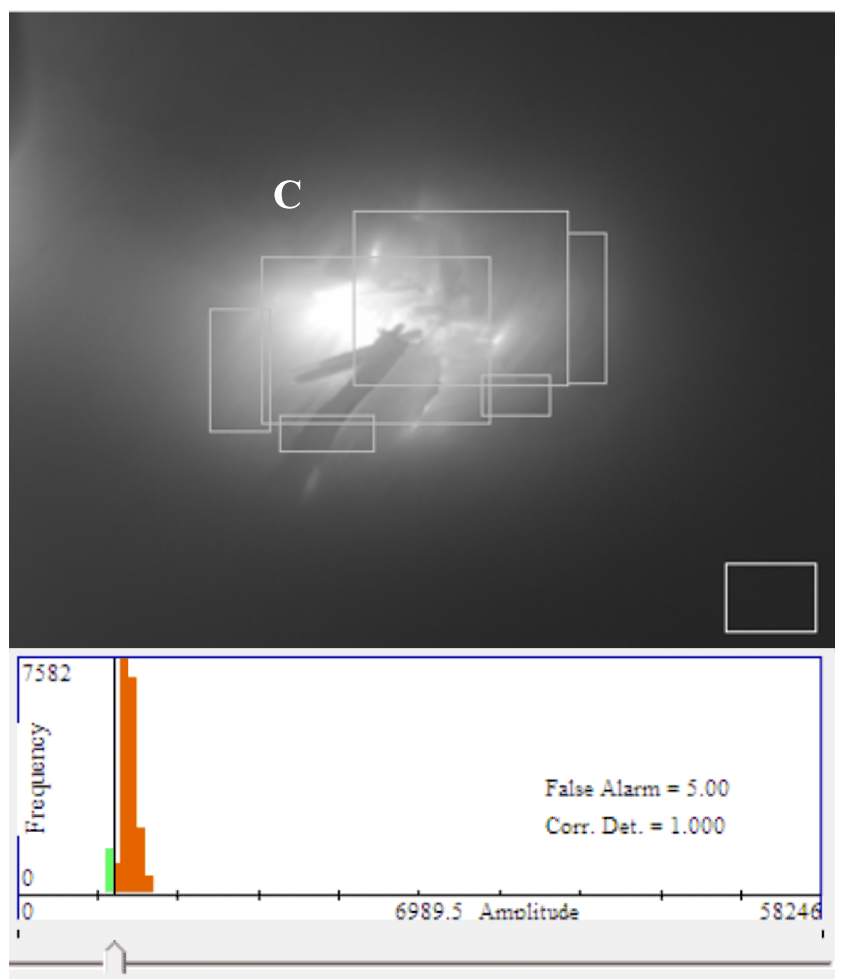

Fig. 4. Front surface source image and its histogram (SC7600 IR imager, piezoelectric stimulation, $30 \mathrm{kHz}, 130 \mathrm{~W}$ ).

magnetostrictive test that can be explained by a higher frequency of ultrasound. It is interesting that the exfoliation A remained cold in this test, probably, due to no (weak) friction.

To characterize detection reliability, a signal-to-noise ratio (SNR) was trivially determined by using the ThermoFit Pro software. Location of rectangular areas of interest chosen by the operator is shown in Fig. 4 (the sound area was represented by the square in the right bottom). The corresponding histogram shown in Fig. 4 shows that the maximum SNR value is about 150 , and the correct detection is $100 \%$ while the false alarm probability is $5 \%$.

Surprisingly, the SNR values were permanently decreasing in time while the temperature in the defect area was growing up in the course of continuous heating (Fig. 5). This fact can be probably explained by lateral heat diffusion that tends to smash defect temperature patterns with time.

Another finding was that SNR values determined in the same way in the case of magnetostrictive stimulation used to be significantly lower reaching the maximum value of 34 in the image of Fig. 3(b). This probably occurred because of the better temperature resolution of the SC 7600 IR imager that made temperature dispersion (noise) in the chosen sound area quite low. Also, the difference in the used frequencies $(30 \mathrm{kHz}$ of piezoelectric stimulation against 22 $\mathrm{kHz}$ of magnetostrictive stimulation) may contribute to differences in SNR values. 


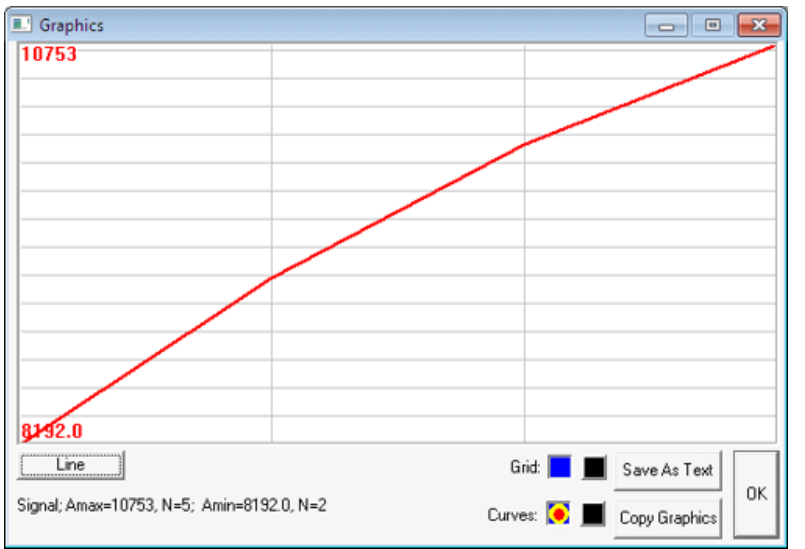

(a)

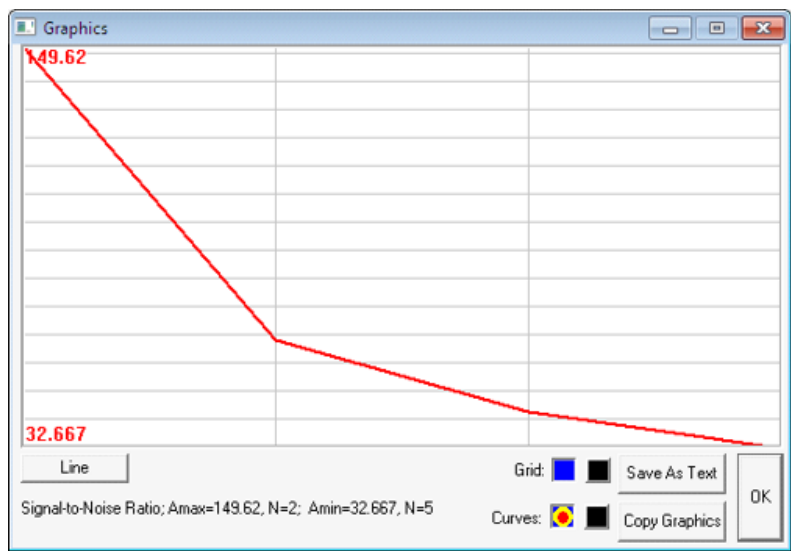

(b)

Fig. 5. Evolution of sample temperature (a) and signal-to-noise ratio (b) in time (SC7600 IR imager, piezoelectric stimulation, $30 \mathrm{kHz}$, $130 \mathrm{~W})$.

\section{Conclusions}

Ultrasonic IR thermography may take advantage of both piezoelectric and magnetostrictive devices in order to input powerful ultrasound into materials under test. Both types of stimulators imply a resonant principle of operation and generally are supposed to produce close results. A coupling technique is important to ensure a nondestructive character of testing with both types of stimulation, although this requirement may be more relaxed in the case of magnetostrictive technique. Piezoelectric devices are commercially available, robust and comfortable in operation. Magnetostrictive devices may be preferable when dealing with high power ultrasound (over $1 \mathrm{~kW}$ of electrical power). Also, due to their lower figure of merit, they might produce a wider range of frequency sweeping, thus, better suppressing undesirable standing waves. It has been also found that a choice of an IR imager may affect achievable signal-to-noise ratio values, namely, IR imagers of a higher temperature resolution might provide better results due to lower noise.

\section{References}

1. K.L. Reifsnider, E.G. Henneke, and W.W. Stinchcomb, "The mechanics of vibrothermography", in: Mechanics of nondestructive testing, ed. By W.W Stinchcomb, Plenum Press, pp. 249-276, New York 1980.

2. A. Dillenz, Th. Zweschper, and G. Busse, "Elastic wave burst thermography for NDE of subsurface features", Insight 42, 815-817 (2000).

3. Th. Zweschper, A. Dillenz, and G. Busse, "Ultrasound lock-in thermography - a defect selective method for the inspection of aerospace components", Insight 43, 173-179 (2001).

4. Th. Zweschper, A. Dillenz, and G. Busse, "Ultrasound lockin thermography - an NDT Method for the inspection of aerospace structures", Proc. $64^{\text {th }}$ Eurotherm Seminar "Quant. IR Thermography”, pp. 212-217, Reims, 2000.

5. A. Dillenz, Th. Zweschper, and G. Busse, "Phase angle thermography with ultrasound burst excitation", Proc. $64^{\text {th }}$ Eurotherm Seminar "Quant. IR Thermography", pp. 247-252, Reims, 2000.

6. L.D. Favro, X. Han, Z. Ouyang et al, "IR imaging of cracks excited by an ultrasonic pulse”, Proc. SPIE 4020, 182-185 (2000).

7. M.W. Burke and W.O. Miller, "Status of vibroIR at lawrence livermore national laboratory", Proc. SPIE 5405, 313-321 (2004).

8. M. Morbidini, P. Cawley, T. Barden, D. Almond, and P. Duffour, "Prediction of the thermosonic signal from fatigue cracks in metals using vibration damping measurements", $J$. Appl. Phys. 100, 104905 (2006).

9. J. Renshaw, S.D. Holland, and R.B. Thompson "Measurement of crack opening stresses and crack closure stress profiles from heat generation in vibrating cracks", Appl. Phys. Lett. 93, 081914 (2008).

10. C. Homma, M. Rothenfusser, J. Baumann, and R. Shannon, "Study of the heat generation mechanism in acoustic thermography", in: Review of progress in quantitative nondestructive evaluation 25, ed. by Thompson DO, Chimenti DE, American Institute of Physics, pp. 566-573, Melville, NY, 2006.

11. X. Guo and V.P. Vavilov, "Crack detection in aluminum parts by using ultrasound-excited infrared thermography", Infrared Phys. Techn. 61, 149-156 (2013).

12. J.M. Milne and W.N. Reynolds, "The non-destructive evaluation of composites and other materials by thermal pulse video thermography", Proc. SPIE 520, 119-122 (1984).

13. N.P. Avdelidis, B.C. Hawtin, and D.P. Almond, "Transient thermography in the assessment of defects of aircraft composites", NDT \& E International 36, 433-439 (2003).

14. S. Shepard, "Understanding flash thermography", Mater. Eval. 454, (2006).

15. V.P. Vavilov, V.S. Khorev, and A.O. Chulkov, "Ultrasonic infrared testing of impact damage in composites: Analysis of peculiarities. Testing”, Diagnostics 13, 197-201 (2012) (in Russian). 